DOI: https://doi.org/10.47405/mjssh.v6i1.587

\begin{tabular}{|c|c|}
\hline 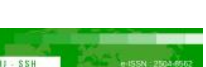 & Malaysian Journal of Social Sciences and Humanities (MJSSH) \\
\hline Malaysian Journal of & Volume 6, Issue 1, January 2021 \\
\hline (Mu-ssH) & e-ISSN : 2504-8562 \\
\hline & $\begin{array}{l}\text { Journal home page: } \\
\text { www.msocialsciences.com }\end{array}$ \\
\hline
\end{tabular}

\title{
Everyday struggle - Gender Equal Working Conditions for Females in Cambodia?
}

\author{
Nina Weimann-Sandig1 \\ ${ }^{1}$ University of Applied Sciences for Social Work, Education and Nursing Dresden, Germany \\ Correspondence: Nina Weimann-Sandig (nina.weimann-sandig@ehs-dresden.de)
}

\begin{abstract}
Compared to other East Asian countries, Cambodia has relatively high female labor force participation rates. More than 75 percent of women are working, compared to the regional average of $60 \%$ (World Bank 2018). However, the educational background of many people, especially females coming from rural areas, is still poor in Cambodia, Therefore, the garment industry and the construction sector offer low-threshold job possibilities for less educated females in order to gain a stable income. Whereas the garment industry is defined as dominated by females, the construction sector is still characterized as typical male sector. The study aims to ask to what extend less educated females, coming from poor areas of Cambodia can enjoy and benefit from their work lives. In addition, gender stereotypes and gender inequality concerning the female workforce in garment and construction are presented. As previous research has focused on quantitative analysis, this study tried to explore perceptions of females working in the garment and construction sector by using the qualitative method of focus group discussions.
\end{abstract}

Keywords: gender inequality, gender and labor market, reconciliation of work and family, qualitative social research

\section{Introduction}

Analyzing the possibilities women are facing towards labor market access does not simply mean to understand the labor market structures of a country. Instead, the existing labor market structures are only one corner stone that has to be kept in mind. Gender Equality is moreover characterized by the existing social norms and structures, cultural attitudes and religious patterns of a country. Cambodia as an example - is still strongly influenced by its past while trying to meet the demands of developing, industrialized countries. Cambodia's transition over the last 30 years is characterized by industrialization, a growing construction boom and a developing service sector. Agriculture still plays an important role but is declining as a share of economic output and of jobs. The living standard has developed towards lower-middle-income status and the poverty rate is decreasing. Whereas $47 \%$ of the population in 2007 suffered from poverty, this figure had fallen to 13.5 percent by 2014 (World Bank, 2019). Nevertheless, high numbers of people still live just above the poverty line, and about 4.5 million people are considered to be economically vulnerable, namely they have a high risk of falling into poverty (World Bank, 2019). Specially affected groups are low-educated people, inhabitants of rural areas and when focusing on gender, women. Therefore, gender inequality is still a major topic in Cambodia and will remain so during the coming years. Most interestingly, Cambodia has one of the highest female labor market participation rates in the Asian region (The World Bank, 2019). However, recent labor market developments are characterized by gender segregation, with female-dominated and 
male-dominated branches. While women are preferred workers in garment factories, men dominate the construction sector, for example. Inclusive growth seems to be one of the major challenges (Asian Development Bank, 2013). Although there have been made tremendous efforts to improve the educational system in Cambodia, there is still progress to be made. Nearly $8 \%$ of the female population between 15 and 19 years drop out of school before Grade 7. When looking at the age cohort of women between 30 and 34 years, 27 percent have no formal education at all (World Bank, 2016). Like nearly no other country, Cambodia still has to bear the consequences of the past Khmer Rouge regime, especially when talking about gender inequality. The rise of the Khmer Rouge regime not only shifted the economic structure towards low-skilled farming. Education mainly consisted of teaching central Communist ideas, and keeping people illiterate was a means of ensuring compliance with the ruling forces. Women had the same workload in the fields and on farms as men. Women faced even more difficult circumstances, though. Forced pregnancy, along with sexual abuse and violations were a common way of warfare in Cambodia and deeply influenced the picture of women (Lobato, 2016). This history is relevant today, as international studies show that a high percentage of the Cambodian population still displays post-traumatic stress disorder (Agger, 2015). Moreover, the traumatization can be described as intergenerational transmission, as victims of the Khmer Rouge regime show high aggressive potential and low frustration tolerance. This influences the socialization of their children and the next generation (Field et al., 2013). It also affects social attitudes towards men and women, including humiliation of the female body and soul, and creates long-lasting gender stereotypes (England 2005). One of the most important industries for employing women - not only in Cambodia but in many other developing countries - is the textiles and garment sector. Over the last 40 years, garment production has shifted to developing countries. This created new opportunities for females, especially less-educated ones, to enter the labor force (Lopez-Acevedo/Robertson, 2016). The garment industry is of great importance for the Cambodian economy. International companies from all over the world shifted significant parts of their textile production to Cambodia. During the last years, human rights offences and bad working conditions lead to international demands for better social standards at garment factories (Asean Today, 2019; The Guardian, 2017). This resulted in an increased cooperation between garment companies and the International Labor Organization (ILO). It is to be asked, if this led to a general improvement of working conditions and in particular to a better protection of female workers.

\section{Theoretical Background}

In order to understand the meaning of societies in transition, it is insufficient to purely name the new developments and contrast them with traditional ways of life a country has established during the last centuries. Although at first sight women play an important part in the Cambodian labor market, a closer look shows that the traditional and cultural, gender-based role models lead to an unequal labor market engagement and an unequal distribution of benefits the females and males derive from. This research aims to explore and understand the challenges and constraints women from different social groups are facing, not only with regard to labor market access, but also about the social expectations they have to meet. The presented research is part of a World Bank project done in 2019. The qualitative paradigm of empirical social research is dealing with different methodological backgrounds that have one thing in common: they believe that either through interaction or communication people not only influence but shape their social environment (Girtler, 1992). Narrative, qualitative methods try to reconstruct this process. This assumes a different understanding of the researcher's role: while quantitative social research requires the greatest possible objectivity of the researcher, the qualitative paradigm neglects this (Brinkmann, Jacobsen and Kristiansen, 2014). The communicative process shapes a relationship between the researcher and the people being examined. The better this relationship is, the more the principle of openness, which is mandatory for qualitative social research, can be realized (Gummesson, 1991). Nevertheless, it requires a well-developed strategy and the use of appropriate research methods to gain high quality data. As shown above, the constraints and challenges women face with regard to labor market access in Cambodia require differentiated consideration. First of all, it has to be kept in mind that there are different groups of women in each society. There are, for example, differences between well-educated and poorly educated females, mothers and women without children, women living in rural areas and those who live in cities. 
Therefore, it was necessary to use a research method that aimed not only to understand a single perception, but collective perceptions, thus the modern method of focus group discussions was selected (Mangold, 1967).

In contrast to focus groups that are often held in consumer or marketing research (Henseling, 2006) or are used to analyze existing (organizational or political) concepts, the sociological method of group discussions deals with a different approach: focus group discussions aim to explore collective knowledge or experiences of natural groups (Bohnsack, 2010). The implicit knowledge that people with similar biographies share is what researchers try to identify (Weimann-Sandig, 2014). Focus group discussions concentrate on natural groups who have major socio-demographic indicators in common. Women working as shift workers in garment production could be named as one group, for example. They share similar work experiences, have related educational backgrounds, and face the same challenges. This makes it possible for them to talk freely within a focus group discussion, although participants do not know each other (Weimann-Sandig, 2014). Unlike focus groups in marketing or consumer research, the interviewer has to step back and to define his or her role as a moderate only. The whole discussion process is quite open and unstructured. Major topics are given to participants who decide by their discussions which direction they want to follow. The researcher has a neutral position, meaning answers are not judged as right or wrong and interviewees are not led in a particular direction. In contrast to the well-known theoretical sampling (Glaser and Strauss 1976) in qualitative research that aims to reconstruct typical cases by identifying contrasting and common issues in individual experiences and perceptions, the research process in Cambodia has to start from a different perspective. The strategy of so-called deviant sampling (Rods, 2012), which deals with extreme and deviant groups, helped to meet the challenges of a research project limited in time and the need to explore as much perceptions as possible within a limited number of focus groups.

In particular, qualitative research aims to reconstruct typical cases by identifying contrasts and common issues in individual experiences and perceptions. The methodological point of reference can be seen in the deep insights given in the reconstructions of typical cases of female labor market success with regard to the garment and construction sector. Together with a local research firm, four focus group discussions were held in the regions of Phnom Penh and Siem Reap. Each group had a minimum of six and a maximum of nine participants and lasted between two and three hours. For every focus group discussion, survey instruments provided detailed thematic guidelines and a questionnaire of less than one page to be filled out by the focus group participants (largely to gather basic socio-demographic information). All material gathered during these focus group discussions was transcribed and translated into English immediately following the discussion and then systematically coded with the help of the qualitative software MAXQDA. The qualitative data analysis was done by combining elements of qualitative content analysis and hermeneutical method (Kuckartz, 2018). This method enables researcher not only to identify, analyze and compare the contents of the different focus group discussions but also to analyze the communication within the discussions. This helps to identify those topics that are more relevant than others for special groups of females. In difference to other methods of qualitative content analysis (Mayring, 2008; Gläser \& Laudel, 2010), the meaning of not building the analytical framework a priori but, instead, based on the empirical research is essential for Kuckartz's idea. To sum it up, doing focus group discussions requires having experienced moderators who not only have a deeper knowledge about the research topics but also have high communicative and social skills. The following section presents the detailed findings of the focus groups corresponding to the following central research questions.

i. What reasons are important for females to apply for jobs in the garment or construction sector?

ii. How is the general work atmosphere described?

iii. Which gender-based inequalities can be observed in both work fields?

\section{Results}

The focus group discussions provided interesting insights into the limited labor market possibilities offered to low-educated females in Cambodia. In order to provide a detailed description, the first part 
of the empirical results is dealing with the perceptions of female garment workers, whereas the second part considers those of females working in construction.

"Everybody is able to sew" - Female motives of working in the garment sector and the challenges of female internal work migrants

Garment factories seem to be especially attractive for females from rural areas because they provide job possibilities for low-skilled workers. As the educational background of females in rural areas is much lower as of those in urban districts (The Borgen Project, 2018), the formal employment possibilities are quite limited. The female focus group discussions describe garment work as a lowthreshold possibility to step into the formal labor market and to gain a regular income. On-the-job trainings are quite short, lasting a day or two and easy to handle. Women frequently leave their families, including their children, to migrate to regions where the factories are located. Grandparents or elder relatives fill in the care gap while the mothers are engaged in better jobs than those available in their home regions.

Female Garment Worker 4: Mostly, there are only grandparents and grandchildren or aunt and uncles who take care of our children.

Female Garment Worker 7: It is difficult to find jobs to do. In rural areas, we only grow rice or do farming. We don't have any jobs to do beside this.

Female Garment Worker 4: Besides growing rice, we have to stay home because there are no jobs. But we can't live from growing rice, so we have to come to Phnom Penh. Agriculture in modern times is hard. If we grow rice and receive high prices, it is okay. But the prices are decreasing. We can't even afford to pay for some chemicals and fertilizers. So that is why we are work migrants and come to Phnom Penh.

(Focus group discussion 20, Female internal work migrants, Garment industry, Section 260-264)

The participants suggested that mono cropping incentivizes people to search for jobs in garment factories in other regions, instead of working at rural farms. They noted that rural areas in Cambodia do not provide a variety of farming possibilities, instead relying on one crop type (often rice). This results in limited variety of food, unbalanced nutrition and also malnutrition of smaller children. Therefore, especially mothers decide to leave their families during the week or for whole months, in order to earn an additional income. This means that a large number of female garment workers are internal work migrants with special needs because they have to care for their children and face a quite unbalanced reconciliation of work and family. The results of the focus group discussions reveal that although many factories are not under ILO protection, gender-sensitive working policies or caring for the special needs of females, have not been generally implemented (ILO, 2018). As an example, the care for pregnant women is not provided in many factories. Women who get sick during working times are often not permitted to leave their workplaces because the assembly-line production methods and demanding quotas are not amenable to line members being absent. Team leaders decide if pregnant women are allowed to recover or not, with the ill or pregnant woman having little say in the matter. The participants report that pregnant women often have to do overtime like all the other workers. There is no maternity protection period before the date of birth, so most women work until the last day of their pregnancy. Only a few factories give women the possibility of leaving before the birth.

Moderator: Can you share your perceptions of the working conditions? What happens if you are pregnant? Are you allowed to stop working because you suffered from morning sickness? 
Female Garment Worker 5: No, we need to struggle. I can't remember getting permission to stop. It is up to the team leader to give you permission to stop. And the team leaders want to meet their daily production aims. So we have to work and work and work.

All participants: Yes, we need to struggle.

(Focus group discussion 20, Female internal work migrants, Garment industry, Section 270-2274)

The discussants also highlight the differences between permanent workers and temporary workers as the latter group is less protected than the first one. Especially the healthcare provided for pregnant temporary workers is regarded as insufficient although the National Social Security Fund has been offering health protection for workers since 2016.

Moderator: And what about early leaving? Do you get permission to stop working
several weeks before you give birth or do you stop working when you give birth?

Female Garment Worker 6: Yes, we stop working when we give birth and we are not allowed to stop before, as we are temporary workers. It might be different for permanent workers, but for us it is hard.

Female Garment Worker7: In my case I had to work hard until the day of the birth. As a result, my child was too small and he was weak. I couldn't ask for permission to leave earlier, no chance. After this experience I decided to stop working in this factory. I stayed at home with my baby.

(Focus group discussion 20, Female internal work migrants, Garment industry, Section 622-633)

To sum it up, the qualitative research material proofs that the garment industry provides low-threshold job entries with fixed salaries on the one hand. On the other hand, the study stresses the differences between formal working policies and the reality of female garment workers. Although there have been significant efforts to help garment factories establish better working conditions, more gender-sensitive work is needed. Most interestingly, the strong hierarchical work organization in garment factories leads to a decreasing solidarity between females. Female team leaders are less respected by the garment workers, also seem to have no collective awareness towards their female workers. As most garment workers are female, the lifecycles of women have to be taken into account when thinking of modern working policies. As the discussions show, the Cambodian society still is a male-dominated one but puts great emphasis to the family care work of females. Therefore, in order to meet those expectations, garment factory should support their female workers instead of making their lives more difficult. The discussions proof that female workers tend to step out of labor market when experiencing conflicts because of their roles as mothers and the connected care work. As garment factories need to have stable work shifts, it should be a central aim to build up female friendly working scenarios. The focus group discussions could therefore help identifying central constraints female garment workers are recently facing. A lack of childcare facilities at factories, non-child-friendly policies and practices and limited maternity leave lead to dropouts of female workers. Maybe it could be worth to look at best practice examples in other countries. Germany or Denmark for example provide at least one year of maternity leave, while Canada and Australia offer 18 weeks of fully paid parental leave. Given the importance of reliable and regular relationships between parents and children in the first year of life, for the healthy development of children (Grossmann \& Grossmann, 2004), both current and future workers would benefit from greater support for motherhood. In addition, the hierarchical system within the factories seems to sharpen gender inequality as leading positions are mostly given to males. Where females have to chance to be team leaders they seem also to abuse their power in order to strengthen their positions. This leads to a missing female solidarity and sharpens gender-based conflicts. Team leaders could be trained to establish a more pleasant working 
environment. The concept of team building could help shaping a better understanding of administrative staff and workers.

\title{
Female construction workers - caught in between
}

Before presenting the results of focus group discussions with females working in the construction sector, it is to mention that those discussions had been quite challenging. As mentioned bellowed, the mostly low-educated females showed fears to be judged by their low educational background what meant that they had been repeatedly encouraged to share their opinions and thoughts. Therefore, the empirical material is shorter but of great use: Cambodian females, especially those dropping out of schools and suffering from illiteracy have to be taken under greater governmental protection and consideration.

The construction industry, traditionally male-dominated, has been a source of rapid job growth in Cambodia due to increasing foreign investment. A report by the Ministry of Land Management, Urban Planning and Construction (MLMUPC) states that investment in construction more than doubled between 2018 and 2019. Although the industry has long been dominated by men, recently it has been attracting more female workers. About 20-40 percent of workers in the construction field are women;1 most have limited education and are nearly illiterate, and they have few job opportunities. Therefore, it seemed valuable to have a closer look at women working in construction and hear their perceptions on the quality of these jobs. The sample consisted of married and unmarried women who had been working in construction for more than 10 years. All female participants came from poor, farming areas. Their families were suffering from extreme poverty and could not afford to send their children to school. Physical violence, as well as the need to contribute to the family income as soon as possible, define them all.

\begin{abstract}
Female Construction Worker 3: In my case, my father mistreated my mother badly. My mother had to work very hard. She climbed up the palm tree. Sometimes he hit my mother badly. That's why I said we don't really have different experiences, we all grew up with violence. Because it is the same here in every story. That is why I didn't go to school. And I needed to help. Our teacher used to call me back to school, but I was not allowed to go to school. I had to work on getting the palm juice and produce the palm sugar. The teacher came three times to get me back to school but I had to tell him that I have to stay at home with my mother.
\end{abstract}

(Focus group discussion 25, Women working in the construction sector, Section 231-238)

In accordance with the female garment workers, most women working in construction need to create an own income. In difference, most participants here are Single-Mothers and have no husband they can rely on. As shift work is described as too inflexible to meet the demands of Single Mothers, those females prefer to be absent for several months but have the chance to earn enough money during this period of time to stay at home for the rest of the year. They all have to rely on grandparents or other relatives in order to look at their children as long as they are abroad. They describe themselves as internal work migrants and refer to their early school dropouts in order to explain their motives to work in the construction field. Most of the participants define themselves as nearly illiterate and therefore dependent from doing physically demanding work. Young marriage is very common within the rural population what means that those participants in their early 30 s already have grown-up kids.

Moderator: What grade did you finish, Sister?

\footnotetext{
${ }^{1}$ https://www.channelnewsasia.com/news/asia/asia-s-toughest-jobs-the-women-helping-to-buildcambodia-9040876
} 
DOI: https://doi.org/10.47405/mjssh.v6i1.587

Female Construction Worker 2: I finished Grade 2.

Female Construction Worker 3: I'm 33 years old. I have two children, one boy and one girl and my husband is also a construction worker.

Moderator: Until what grade did you study?

Female Construction Worker3: Until Grade 3.

Female Construction Worker 4: I'm 30 years old. I got divorced when my child was 3 years old. Now my child is 17 years old.

(Focus group discussion 25, Women working in the construction sector, Section 70-80)

Due to the construction boom across the country, the sector provides a stable income for its workers. Work in the construction sector is described as hard, with a lot of physically demanding tasks. Most women are working as plaster mixers, which means that they have to carry heavy packages of cement and they are responsible for mixing it.

Female Construction Workerl: There is pressure, yes. For example, team leaders that blame you when you are slow or when we are late. There are three leaders and two workers, all men. And one of the workers is very strong and fast. In a morning, he finishes 10 bags of cement. But for us, we are the ones that have to carry the cement for him, that is a heavy task.

Female Construction Worker 6: Carrying cement is okay for me, what is hard is carrying the plaster stones.

(Focus group discussion 25, Women working in the construction sector, Section 218-222)

The participants describe the challenges of the construction workplace in detail. Unpaid overtime is common, as are nightshifts. Women often have to dress in the same dressing rooms as their male colleagues, and there are often no separate bathrooms. Verbal sexual harassment and jokes are commonplace for women working in construction. Whereas married women feel more protected from sexual abuse, widows and single mothers report numerous incidents. The team leader's abuse of power in construction also shows great gender inequality. The female respondents feel that they are less protected than their male colleagues, and more often punished. While mixed work teams seem to be quite common, few females feel accepted by their male team members.

Female Construction Worker 4: One day I was working, and I had to carry the sand with water. I said to a colleague: "Please help me put it on my shoulder.' And this guy said, 'See, hiring female workers is useless because they are helpless.' I said, 'Why do you care? The important thing is the contractors hired us as females.' He kept repeating his words and I couldn't bear it any longer. I stopped working and called my manager to get my money and leave. The manager tried to help me by telling the guy stop being impolite. This guy just said, 'You believe that fucking crazy lady?'

(Focus group discussion 25, Women working in the construction sector, Section 231-233)

Respondents felt that both gender-related productivity differences and pure gender bias underlie observed gender wage gaps. Some explain the gender wage gap as being due to men's greater physical capacities. Others, however describe unequal pay for equal work. Standardized wages are not 
common, instead wages for same tasks vary by up to 5,000 Riel (\$1.25) per day. This might not sound like much, but as daily wages are not more than $\$ 4$ for women in construction, this difference influences their monthly salary. Regular payment is not mandatory in the construction industry, as most participants declare. All of them have already experienced wage losses because of the arbitrary decisions of their contractors. With regard to career opportunities, the respondents did not report any women in leading positions. Team leader positions and middle management jobs are only given to men. Because of the dangerous and physically demanding work in the construction industry, all participants worry about their futures. Unsafe working conditions and the heavy work have led to serious accidents, as well as deaths of female workers. Single mothers are particularly worried as there is no social protection for their children. Although there have been several reports about the bad working conditions of females in the construction sector, respondents feel there are almost no laws that help to protect women working in the construction sector. All participants claim the need of implementing a minimum wage as well as laws on fixed monthly incomes as well as equal salaries for men and women. Employers tend to ignore the female need to reconcile work and family as there is no discussion in the workplace about children of construction workers. Childcare must be organized within families what leads to desperate situations. Some participants told that their children had been violated by relatives during their absence. This situation is unbearable not only for mothers but also for their children. When asked about their living conditions, the participants stress that working in the construction sector provides enough money to survive and also to stay at home for several months but none of the participants is able to do any savings. Construction work is therefore defined as leading a hand-to-mouth existence.

\begin{abstract}
Female Construction Worker 8: There are some good things to share about working in construction. The best thing is that we are doing paid work. Staying at the family farm means working without income. The companies pay us money, so we can have enough to eat. The negative aspect is that we are often not paid by the team leaders. It really depends on the team leaders; if they are good people, they will give us the agreed wage. If the team leader is bad, they don't pay us, so we will face difficulties. Sometimes we have to borrow money to buy food. And when we have to buy a motorbike for riding to work, we have to borrow money. And of course, we can only buy used things. Used motorbikes or used furniture.
\end{abstract}

(Focus group discussion 25, Women working in the construction sector, Section 400-408)

The nature of construction jobs - low wages and remote work - negatively affects the future of female construction workers' children. When asked about future expectations for their kids, all the participants want their children to get a better education. However, they are aware that leaving their children in a rural area means they will attend a lower quality school. As no one can afford to pay school fees, the help of NGOs and monks plays an important part in helping their children gain access to education, including vocational education. Most participants are aware that even their children won't be able to break out from the vicious circle of poverty. The construction sector was chosen as it is a source of job growth and can be defined as a second work field where females without educational background are able to get into formal employment. The construction sector in Cambodia still meets no international working and safety standards and is characterized by a wage gap that has been steadily growing over recent years (Gavalyugova \& Cunningham, 2019). To leave rural poverty and earn a higher income, women must accept demanding working conditions and are suffering from sexual harassment. The focus group discussions reveal the exhausting working conditions in this sector. As most of the females have less education than those in garment factories, they have to accept nearly every work without being offered formal working contracts or guaranteed wages. Again, the discrepancies between formally fixed working conditions and real work practices became evident. Females working in the construction sector would need legal protection as well as NGO's who care about their well-being. Recently, all workers lack of healthcare services and protection as well as insurance systems that help them to meet their everyday lives when getting hurt during their work. 


\section{Conclusion}

Although only two work fields have been presented in the article, it should have become clear that doing formal work for less educated females in Cambodia is still extremely challenging. Indicators like local disparities and motherhood status make it difficult for females to be constantly employed. Single Mothers seem to be even more vulnerable than others are, because they have nearly no chance to be formally employed. Therefore working in construction often means the only chance to create a regular income. Actually, most single mothers in Cambodia still live under the poverty line (Heuveline \& Hong, 2017). Single mothers are less flexible in being able to work shifts at factories, or in covering standardized working times which hasn't been taken under consideration by modern working policies in Cambodian companies and factories yet. Being illiterate also limits the job perspectives of females and leads to work in garment factories or the construction sector. As Cambodia is increasingly becoming a working society and the welfare system is still nascent, it is important to develop strategies to increase the labor participation of these vulnerable groups. The discussion across the focus groups stress women's differential expectations of time use across the life cycle. While single women want to work to earn enough money to meet their individual interests and needs, marriage heavily influences the life course of a woman. At this time, childcare, but also the care of elder relatives, is their focus. Married women feel socially obligated to reconcile work and family issues; indeed the traditional behavior of most families prioritizes women's role as mother and caregiver. As the mother is seen as the person most responsible for the development of the children, most women feel that their families or in-laws are critically observing their compliance with this role (Ledgerwood, 1994). The presented results should encourage a general rethinking of female education in Cambodia. Girls and young females coming from rural areas need to be given more protection and support in order to reach not only basic education but have the chance to take part in secondary and higher education. Research on educational inequality proofs the need of developing targeted strategies for females in countries where gender inequality is still high in all social fields (UN Women, 2016). In addition, local disparities highly influence the quality of education what often leads to vicious circles of poverty. On the other hand societies need to provide low-threshold job opportunities for less qualified people. Therefore, controlling the mismatch of formal working policies and real everyday lives in garment factories and the construction sector should be mandatory in Cambodia. It would help females to feel more protected and could improve the economic situation of the country as females could be a constant part of the labor market.

\section{References}

Asian Development Bank (2013): Gender Equality in the Labor Market in Cambodia. Asian Development Bank.

Asian Development Bank (2018): Cambodia's New Technical and Vocational Education and Training Policy. Edited by Asian Development Bank. Available online at https://www.adb.org/sites/default/files/publication/401691/adb-brief-089-cambodia-new-tvetpolicy.pdf.

Asian Development Bank (2018): Cambodia's New Technical and Vocational Education and Training Policy (Policy Brief, 89). Available online at https://www.adb.org/publications/cambodia-newtvet-policy, checked on 3/6/2020.

Bohnsack, R. (2010) (in German): Rekonstruktive Sozialforschung. Berlin/Leverkusen.

Cambodian female workers in Nike, Asics and Puma factories suffer mass faintings. In The Guardian (2017). Available online at https://www.theguardian.com/business/2017/jun/25/femalecambodian-garment-workers-mass-fainting, checked on 10/30/2020.

Cambodian garment factories improve conditions but rights violations continue (2020). In Asean Today, 10/29/2020. Available online at https://www.aseantoday.com/2019/01/cambodiangarment-factories-improve-conditions-but-rights-violations-continue/, checked on 10/30/2020.

England, P. (2005): Gender Inequality in Labor Markets: The Role of Motherhood and Segregation. In Social Politics: International Studies in Gender, State \& Society, 12(2), 264-288. https://doi.org/10.1093/sp/jxi014

Girtler, R. (1992) (in German): Methoden der qualitativen Sozialforschung. Wien et al. 
Grossmann, K. G., K.E. (2004) (in German): Bindungen - das Gefüge psychischer Sicherheit. Stuttgart.

Gummeson, E. (1991): Qualitative methods in management research. Newbury Park et al.

Heuveline, P. (2017): Household structure and child education in Cambodia. In International Journal of Population Studies. Available online at DOI: 10.18063/ijps.v3i2.309, checked on 3/6/2020.

International Labor Office (2018): Employment and environmental sustainability in Asia and the Pacific. ILO. Available online at https://www.ilo.org/wcmsp5/groups/public/---asia/---robangkok/documents/publication/wcms_624556.pdf, checked on 6/17/2019., checked on $11 / 19 / 2019$.

International Labor Office (2019): Improving women's access to old-age pensions. Cambodia and Viet Nam. Available online at

https://www.usp2030.org/gimi/RessourcePDF.action;jsessionid=1vCoKuV6PySiaPZVx41riQk M6EjWsEjmnoL1PjhceDSk-drNIWAm!-1751551395?id=55605.

Kawazu, E. C., \& Kim, H. (2019): Mass fainting in Cambodian garment factories. In Global Epidemiology (Volume 1). Available online at https://doi.org/10.1016/j.gloepi.2019.100008, checked on 11/19/2019.

König, R. (1967): Handbuch der empirischen Sozialforschung. Band I.

König, R. (Ed.) (1973): Geschichte und Grundprobleme der empirischen Sozialforschung. 3. Aufl. Stuttgart: Enke (dtv 4235, Wissenschaftliche Reihe).

Ledgerwood, J. (1994): Gender Symbolism and Culture Change: Viewing the Virtuous Woman in the Khmer Story 'Mea Yoeng". In Cambodian Culture Since 1975: Homeland and Exile, pp. 119128. Available online at http://www.seasite.niu.edu/khmer/ledgerwood/women.htm, checked on $10 / 19 / 2019$.

Mangold, W. (1973) (in German): Gruppendiskussionen (. In Rene König (Ed.): Geschichte und Grundprobleme der empirischen Sozialforschung. 3. Aufl. Stuttgart: Enke (dtv 4235, Wissenschaftliche Reihe), pp. 209-225.

Robertson, R., Acevedo, G. L., \& Savchenko, Y. (2018): Globalisation and the Gender Earnings Gap: Evidence from Sri Lanka and Cambodia 1992-2015. Edited by IZA Discussion Paper. IZA (11821). Available online at http://ftp.iza.org/dp1 1821.pdf, checked on 7/2/2019.

Schmillen, A. D., Tan, M. L, Abdur Rahman, Amanina Lnu, Shahrul Natasha, Weimann Sandig, N. (2019): Breaking Barriers: Toward Better Economic Opportunities for Women in Malaysia. The World Bank. Washington D.C. Available online at Washington.http://documents. worldbank. org/curated/en/734461569247873555/Breaking-

Barriers-Toward-Better-Economic-Opportunities-for-Women-in-Malaysia, checked on $11 / 19 / 2019$.

Schmillen, A., \& Weimann-Sandig. N. (2018): Perceptions of Precariousness. A Qualitative Study of Constraints Underlying Gender Disparities in Mongolia's Labor Market. The World Bank. Washington D.C.

Schoyerer, G., \& Weimann-Sandig, N. (2015) (in German): Family Day Care in Germany - the gap between vision and reality. In Journal of Early Childhood Education (JECER) (4), pp. 2-21.

The Borgen Project (2018): Girls education in Cambodia fights inequality and rural isolation. Available online at https://borgenproject.org/girls-education-in-cambodia/, checked on $10 / 30 / 2020$.

The Oxford Handbook of Qualitative Research (2014).

The World Bank (2019): Gender Data Portal. Cambodia. The World Bank. Available online at http://datatopics. worldbank.org/gender/country/cambodia, checked on 10/19/2019.

UN Women (2016): Pervasive Gender Inequality in Rural Areas. Available online at https://georgia.unwomen.org/en/news/stories/2016/04/pervasive-gender-inequality-in-ruralareas, checked on 11/05/2020.

World Bank (2017): Gender Data Portal. Available online at http://datatopics. worldbank.org/gender/country/cambodia, checked on 07.

World Bank (2019): The World Bank in Cambodia. Overview. World Bank. Available online at https://www.worldbank.org/en/country/cambodia/overview, checked on 7/3/2019.

World Economic Forum (2017): The global gender gap report 2017. World Economic Forum. Available online at http://www3.weforum.org/docs/WEF_GGGR_2017.pdf, checked on $7 / 3 / 2019$. 